\title{
Orientasi Kewirausahaan dalam Kinerja UMKM di Jember
}

\author{
Enny Noegraheni Hindarwati *, Agus Rahayu, Lili Adi Wibowo \\ Doktoral Manajemen, Universitas Universitas Pendidikan Indonesia, Bandung, Indonesia \\ *enny_noegraheni@upi.edu
}

\begin{abstract}
The entrepreneurial orientation that affects the performance of Micro, Small and Medium Enterprises (MSMEs) in Jember is a research objective. The study population was 172 micro, small and medium enterprises in Jember. This research uses 100 respondents with simple random sampling technique. The research respondents were the owners of the MSME as informants. Collecting data by distributing questionnaires to 100 respondents. The collected data were analyzed using Structural Equation Modeling (SEM) Partial Least Square (PLS) software. The results showed that the autonomous dimension had a significant effect on the performance of MSMEs, while the other dimensions of entrepreneurial orientation: innovation, proactivity and risk had no significant effect.
\end{abstract}

Keywords: Entrepreneurial Orientation, Performance, MSMEs.

\section{PENDAHULUAN}

Kontribusi Usaha Mikro Kecil dan Menengah (UMKM) terhadap Produk Domestik Bruto (PDB) Indonesia di atas $50 \%$, sehingga UMKM berperan dalam pertumbuhan ekonomi di Negara Indonesia. (http://www.depkop.go.id/data-umkm).

\section{Kementerian Keuangan} RI mengungkapkan bahwa pandemi Covid-19 mulai berdampak pada industri pengolahan dan sektor ekonomi usaha kecil sejak bulan April 2020 (Budastra, 2020). Kebijakan pemerintah memberlakukan Pembatasan Sosial Berskala Besar (PSBB) dan Work From Home (WFH) berdampak pada penurunan kinerja UMKM (Hadi \& Supardi, 2020). Pembatasan tersebut memiliki efek yang lebih parah terhadap UMKM daripada perusahaan besar. Hal ini dikarenakan sebagian besar UMKM mempunyai sumber daya, finansial dan teknis yang terbatas (Laufs \& Schwens, 2014), cenderung memiliki modal, asset dan tingkat produktivitas yang lebih rendah daripada perusahaan besar. Survei Bank Indonesia (BI) menyatakan bahwa dampak pendemi Covid19 menyebabkan $72,6 \%$ pelaku usaha mengalami penurunan omzet dan kesulitan dalam hal permodalan (https://www.inews .id). Penurunan terhadap penjualan dialami oleh $95 \%$ pelaku usaha berdasar survei Lembaga Ilmu Pengetahuan Indonesia (LIPI). Dari data Kemenkop RI bahwa UMKM yang mengalami dampak sangat serius sebanyak 37.000 pelaku usaha dengan adanya penurunan penjualan sebesar $56 \%$. Permasalahan pelaku usaha berasal dari berbagi aspek, diantaranya aspek pembiayaan sebesar $22 \%$, aspek distribusi sebesar $15 \%$ dan pelaku usaha mengalami kesulitan mendapatkan bahan baku mentah sebanyak $4 \%$ terutama adanya pemberlakuan program pembatasan sosial. (https://www. cnnindonesia.com).

Pertumbuhan ekonomi Jawa Timur juga melemah karena pandemi Covid-19 berdampak penurunan sebagian besar kegiatan usaha yang ada di Jawa Timur 
(http://diskopukm.jatimprov.go.id/berita?per _page=126). Tahun 2019 PDRB Jawa Timur yang mencapai Rp2.019 triliun, sebesar Rp1.290 triliun berasal dari kinerja UMKM. Namun pada 2020 mengalami perubahan sangat drastis, yang berlangsung dalam waktu yang relatif pendek. Pada pertengahan bulan Maret 2020 sampai Mei 2020, kebijakan pemerintah social distance dan stay at home telah mengubah kondisi kehidupan UMKM Jawa Timur, mengalami kerugian hampir $100 \%$ (Radar Surabaya, Jawa Pos 1 Mei 2020). Para pelaku UMKM seperti makanan kemasan dan oleh-oleh, souvenir, batik, dan berbagai industri rumahan di beberapa kabupaten di Jawa Timur terpaksa tutup. Penerapan PSBB (Pembatasan Sosial Berskala Besar) di Jawa Timur membuat sektor UMKM makin terguncang terutama industri makanan dan minuman, industri kreatif dan pertanian.

Kondisi pada UMKM yang mengalami goncangan menimbulkan kekhawatiran permasalahan semakin mendalam pada keberlangsungan UMKM. Pandemi Covid-19 sangat mengejutkan pelaku usaha sehingga mendorong berpikir panjang dalam menyusun rencana, mengamankan aset dan modal, serta berupaya bisnisnya tetap berjalan dengan modal kecil dan perputaran pendapatan (cash flow) yang juga kecil. Pelaku UMKM harus mempunyai fleksibilitas dan menggali peluang baru (Davidsson, 2015) dan mengembangkan strategi untuk keberlanjutan bisnisnya. Walaupun entrepreneur memiliki daya juang, motivasi dan spirit kerja dengan target pencapaian yang terukur, kondisi krisi saat ini berdampak pada penurunan omset penjualan. Kementerian Koperasi dan UKM di Indonesia (UMKM, 2018) mempunyai misi menopang kemandirian ekonomi UMKM, memperluas kesempatan kerja dan mendorong pertumbuhan ekonomi serta mengentaskan kemiskinan. Kinerja UMKM memerlukan dukungan peran orientasi strategis, jaringan sosial, berbagi pengetahuan, dan organisasi inovasi (Muafi, 2020). Penemuan, pengembangan dan implementasi ide-ide baru sebagai pendorong penting dari vitalitas dan kelangsungan hidup jangka panjang perusahaan (Garud, Tuertscher, \& Van de Hen, 2013) dan berkelanjutan (Curado, Muñoz-Pascual, \& Galende, 2018).

Penelitian difokuskan pada UMKM dan bagaimana para pelaku usaha berinteraksi selama krisis, mengidentifikasi tindakan dan strategi yang tepat. UMKM yang berorientasi kewirausahaan tinggi cenderung mencari peluang baru dan memperkuat posisi daya saing (Covin \& Miles, 1999), sebagai kekuatan penting yang dapat mendorong pertumbuhan perekonomian nasional dan inovatif (Lawson \& Samson, 2001). Oleh karena itu dilakukan penelitian dengan tujuan untuk mengetahui pengaruh orientasi kewirausahaan terhadap kinerja UMKM di Kabupaten Jember. Manfaat penelitian diharapkan dapat menginspirasi para peneliti untuk mengkaji lebih lanjut pentingnya orientasi kewirausahaan bagi pelaku UMKM.

\section{Resources Based View (RBV)}

Resource Base View (RBV) Theory, merupakan teori yang memandang bahwa organisasi adalah kumpulan sumber daya (Panrose, 1959), sedangkan daya saing perusahaan karena adanya perbedaan sumber daya yang dimiliki masing-masing perusahaan (Barney, 1991). Teori ini mempercayai kekuatan utama adalah faktor sumber daya internal perusahaan sehingga dapat meningkatkan kinerja dan meraih keuntungan. Perusahaan mempunyai sumber daya internal antara lain aset, kapabilitas, kompetensi, informasi, dan pengetahuan. Implikasi dari teori RBV ini adalah sumber daya yang unik akan memenangkan persaingan. Keunikan sumber daya ini seharusnya tidak mudah ditiru. (Ferreira, Azevedo, \& Ortiz, 2011), kemampuan perusahaan mengubah sumber daya menjadi nilai ekonomi tergantung pada sumber daya dan kapabilitasnya.

Perusahaan mempunyai sumber daya berwujud antara lain pabrik, kendaraan, peralatan dan sebagainya serta sumber daya tidak berwujud misalnya reputasi, keahlian yang dimiliki karyawan, budaya perusahaan. Perusahaan mampu menciptakan nilai tambah 
untuk mencapai keunggulan bersaing jika mempunyai sumber daya tidak berwujud. Sumberdaya tidak berwujud mempunyai nilai tambah jika sulit ditiru pesaing dan kelangkaan dalam memperolehnya. Perusahaan yang berpandangan pada sumber daya dengan menggunakan berbagai strategi untuk mengelola sumber daya internalnya sehingga perusahaan mampu bersaing. (Rumelt, 1991), sumber daya yang menciptakan keunggulan bersaing mempunyai karakterisktik imperfect substitutability dan imperfectly imitable; sedangkan (Barney, 1991), sumber daya perusahaan harus valuable dalam pengertian perusahaan mempunyai nilai dengan memanfaatkan peluang dan meminimalkan ancaman, rare artinya perusahaan menghasilkan suatu produk baik jasa dan atau barang yang tidak mudah ditiru pesaing serta subsituable jika produk yang dihasilkan perusahaan sulit disubstitusikan. RBV memengaruhi secara langsung maupun tidak langsung dalam manajemen strategi (Kor \& Mahoney, 2004).

\section{Orientasi Kewirausahaan}

Pengertian orientasi kewirausahaan (Miller, 1983) adalah keterlibatan perusahaan dalam pasar dengan inovasi produk dan mempunyai keberanian dalam mengambil keputusan yang berisiko dan perusahaan menjadi yang pertama dalam menghasilkan inovasi proaktif, serta kemampuan unggul dibandingkan dengan pesaingnya. (Pérez-Luño, Wiklund, \& Cabrera, 2011), merupakan kebijakan dan praktik yang menjadi landasan keputusan dan tindakan kewirausahaan, fenomena yang memperhatikan proses perencanaan, analisis, pengambilan keputusan dan sekaligus mencerminkan budaya organisasi, sistem nilai dan misi perusahaan. Dimensi orientasi kewirausahaan dalam (Boso, Story, \& Cadogan, 2013) dan (Dess \& Lumpkin, 2005 ) terdiri dari risk taking; autonomy; innovativeness; proactiveness; competitive aggressiveness. Dalam (Wang, 2008), innovativeness; proactiveness; aggressiveness dan risk taking sedangkan menurut (Liu, Ding, Guo, \& Luo, 2014) yaitu proactiveness dan risk taking. Menurut Miller (1983), karakteristik dari orientasi kewirausahaan yaitu keberanian mengambil resiko, perusahaan proaktif dan kemampuan berinovasi.

Orientasi kewirausahaan adalah kemampuan perusahaan mempunyai ide yang kreatif dan memanfaatkan sumber daya sebagai kekuatan internal perusahaan dalam menciptakan inovasi untuk meraih peluang. Beberapa penelitian menyatakan orientasi kewirausahaan berpengaruh signifikan dan positif terhadap kinerja (Al-Dhaafri \& AlSwidi, 2016). Perusahaan yang sangat proaktif dalam menjalankan bisnisnya secara otomatis mendorong tingginya kinerja (Weerawardena \& O'Cass, 2004) sedangkan (Theriou, 2015) menyatakan orientasi kewirausahaan tidak berpengaruh signifikan terhadap kinerja pemasaran.

\section{Kinerja}

Menurut Murphy, Trailer, dan Hill (1996), pengertian dari kinerja suatu perusahaan merupakan konsep multidimensi dari berbagai divisi yang ada. Sedangkan penilaian dalam hal produksi, keuangan atau pemasaran merupakan dimensi dari penilaian kinerja seperti yang dikutip dalam (Sohn, Gyu Joo, \& Kyu Han, 2007). Sedangkan Wolff dan Pett, (2006) dalam segi pertumbuhan dan laba. Kinerja UMKM mengacu pada hasil kegiatan bisnis perusahaan (Kotane \& Kuzmina-Merlino, 2017) yang dapat diukur dengan menggunakan berbagai indikator salah satunya adalah indikator pertumbuhan perusahaan. (Shepherd \& Wiklund, 2009) mengidentifikasi lima ukuran pertumbuhan perusahaan umum yang telah digunakan dalam studi sebelumnya; adalah pertumbuhan dalam penjualan, karyawan, laba, aset, dan ekuitas. Oleh karena itu, kinerja UMKM menggunakan aset, penjualan, dan jumlah karyawan sebagai ukuran pertumbuhan perusahaan (Shepherd \& Wiklund, 2009). 


\section{Orientasi Kewirausahaan dengan Kinerja}

Dalam penelitian Dess dan Lumpkin

(2005) menyatakan bahwa orientasi kewirausahaan mempunyai pengaruh positif terhadap kinerja organisasi, karena agen penggerak keunggulan dan memanfaatkan peluang yang muncul, kunci perusahaan untuk mendapatkan keunggulan bersaing (Pérez-Luño et al., 2011). Keberhasilan kinerja inovasi perusahaan jika menggunakan open outside-in innovation (Inauen \& Schenker-Wicki, 2011). D emikian juga pada UMKM ( $\mathrm{P}$ a rid a, W e s t e r b e r g, \& Frishammar, 2012 ). Menurut Dess dan Lumpkin (2005), dimensi dari inovasi yaitu perusahaan cenderung untuk mendukung ide-ide baru dan terlibat dalam menerapan ide-ide tersebut sebagai kebaruan dalam perusahaan. Inovasi berpengaruh terhadap kinerja (Arshad, Rasli, Arshad, \& Zain, 2014), dan mendorong peningkatan kinerja (Ajayi, 2016). Sedangkan proaktif merupakan kemampuan sikap dalam mengantisipasi dan bertindak demi kebutuhan masa depan. Lumpkin dan Dess (2001) menemukan proaktif berpengaruh signifikan terhadap kinerja.

Pengambilan risiko merupakan dimesi dari orientasi kewirausahaan yang bersedia dan berkomitmen terhadap usaha-usaha yang mempunyai resiko kegagalan tinggi terutama dalam biaya (Friesen \& Miller, 1982). Tingkat risiko yang siap diambil perusahaan untuk penentuan perusahaan (Lumpkin, Cogliser, \& Schneider, 2009). Pengambilan risiko, merupakan tantangan bagi pelaku UMKM karena kondisi kekurangan kapasitas dan sumber daya (Agu, 2018). Dimensi pengambilan resiko dalam orientasi kewirausahaan berkontribusi pada peningkatan kinerja (Karacaoglu, Bayrakdaroglu, \& San, 2012). Otonom menurut Al Mamun dan Fazal (2018) adalah tindakan independen individu dalam menyampaikan visi atau ide, menggali kompetensi untuk kesuksesan. Otonom berpengaruh terhadap kinerja (Bolton \& Lane, 2012)

\section{METODE}

Penelitian ini merupakan penelitian eksplanatory, yang menjelaskan pengaruh antar variabel-variabel dan keterhubungan antar variabel yang diteliti. Waktu mengumpulkan data dari pelaku UMKM secara cross-sectional. Sekaran (2020) populasi merupakan keseluruhan kelompok orang atau kejadian akan dilakukan pengukuran secara kuantitatif dengan karakteristik tertentu sebagai obyek penelitian. Populasi penelitian adalah 172 pelaku usaha suatu komunitas UMKM di Jember. Dengan menggunakan rumus Slovin dengan margin of error (e) 5\%, untuk menghitung banyaknya sampel minimum suatu survei populasi. Jumlah sampel sebanyak 100 pelaku usaha dengan pengambilan sampel secara acak, setiap anggota dari populasi berpeluang yang sama untuk dipilih sebagai sampel. Dari setiap UMKM dipilih pemilik atau manajer sebagai informan/responden dengan pertimbangan karena familiar dengan orientasi wirausahaan karena mereka menentukan kebijakan dan bertanggung jawab terhadap keberlangsungan usaha. Pengumpulan data primer melalui kuesioner yang diisi oleh responden secara langsung.

Untuk menganalisis hubungan antar variabel menggunakan variance Based Structural Equation Modeling (SEM-PLS), setiap variabel diasumsikan mewakili konsep dalam bentuk variabel laten. Dalam Wold (1985), metode Partial Least Square (PLS), dapat menguji hubungan antar variabel walaupun datanya tidak berdistribusi normal multivariat dan menjelaskan ada atau tidaknya hubungan antar variabel laten dengan jumlah sampel relatif kecil (minimal 30 responden). Selain itu $P L S$ juga mampu menganalisa konstruk yang dibentuk dengan indikator refleksif dan formatif, berbeda halnya pada analisis data secara SEM karena akan terjadi unidentified model.

Dalam pengolahan data menggunakan SEM-PLS lebih rumit, karena SEM dibangun oleh model pengukuran (measurement model) dan model struktural (structural model). Pengertian dari model struktural atau yang 
dikenal dengan inner model yaitu model yang menghubungkan antar variabel laten. Sedangkan model pengukuran atau outer model adalah model pengukuran yang menghubungkan indikator dengan variabel latennya.

Tabel 1. Operasional Variabel

\begin{tabular}{|c|c|c|c|}
\hline Dimensi & Variabel & Indikator & Sumber \\
\hline \multirow[t]{4}{*}{$\begin{array}{l}\text { Orientasi } \\
\text { Kewirausahaa } \\
\mathrm{n}\end{array}$} & Inovasi & $\begin{array}{l}\text { Saya sering mencoba } \\
\text { ide-ide baru. } \\
\text { Saya mencari cara } \\
\text { baru untuk } \\
\text { melakukan sesuatu. } \\
\text { Saya melakukan } \\
\text { pengembangan } \\
\text { produk baru. } \\
\text { Saya mengalokasikan } \\
\text { dana untuk } \\
\text { pengembangan } \\
\text { produk baru }\end{array}$ & $\begin{array}{l}\text { (Anwar \& } \\
\text { Ali Shah, } \\
\text { 2020) }\end{array}$ \\
\hline & Autonom & $\begin{array}{l}\text { Saya } \\
\text { memperbolehkan } \\
\text { karyawan untuk } \\
\text { mempraktikkan } \\
\text { ketrampilannya } \\
\text { Saya mendukung } \\
\text { karyawan yang } \\
\text { menghasilkan produk } \\
\text { baru. } \\
\text { Saya memberdayakan } \\
\text { karyawan untuk } \\
\text { membuat keputusan } \\
\text { Saya memberikan } \\
\text { keleluasaan dalam } \\
\text { menjalankan tugas, } \\
\text { seperti penjadwalan } \\
\text { bekerja }\end{array}$ & $\begin{array}{l}\text { Njoroge } \\
(2015)\end{array}$ \\
\hline & Proaktif & $\begin{array}{l}\text { Saya memulai } \\
\text { tindakan baru } \\
\text { Saya yang pertama } \\
\text { kali memperkenalkan } \\
\text { produk } \\
\text { Saya sebagai } \\
\text { pemimpin pasar } \\
\text { dalam } \\
\text { memperkenalkan ide- } \\
\text { ide baru }\end{array}$ & $\begin{array}{l}\text { (Isichei, } \\
\text { Emmanue } \\
1 \\
\text { Agbaeze, } \\
\text { \& Odiba, } \\
2020 \text { ) }\end{array}$ \\
\hline & Resiko & $\begin{array}{l}\text { Saya cenderung } \\
\text { mengambil peluang } \\
\text { yang berisiko tinggi } \\
\text { Saya berani pada saat } \\
\text { ketidakpastian } \\
\text { Saya mengambil } \\
\text { berbagai tindakan } \\
\text { diperlukan untuk } \\
\text { mencapai tujuan }\end{array}$ & $\begin{array}{l}\text { (Isichei et } \\
\text { al., 2020) }\end{array}$ \\
\hline $\begin{array}{l}\text { Kinerja } \\
\text { UMKM }\end{array}$ & $\begin{array}{l}\text { Pertumb } \\
\text { uhan }\end{array}$ & $\begin{array}{l}\text { Usaha saya } \\
\text { mengalami } \\
\text { pertumbuhan } \\
\text { penjualan } \\
\text { Usaha saya } \\
\text { mengalami } \\
\text { pertumbuhan aset } \\
\text { Usaha saya } \\
\text { mengalami } \\
\text { pertumbuhan jumlah } \\
\text { karyawan }\end{array}$ & $\begin{array}{l}\text { (Kiyabo } \\
\& \text { Isaga, } \\
2020)\end{array}$ \\
\hline
\end{tabular}

Sumber : Penelitian (2020)

\section{HASIL DAN PEMBAHASAN}

Hasil penelitian profil responden menunjukan sebagian besar pelaku UMKM berjenis kelamin wanita sebanyak 74 orang dan laki-laki 26 orang, dengan industri pada usaha kuliner sebesar 69 pelaku UMKM. Sedangkan yang berkiprah pada industri kreatif sekitar 31 pelaku UMKM. Sebagian besar baru memulai bisnis dalam kisaran 1-3 tahun sebanyak 53 pelaku UMKM di industri kuliner, sisanya industri kreatif 13 pelaku UMKM. Responden yang diperoleh kebetulan tidak ada yang yang mulai berbisnis dengan waktu usaha antara 3-5 tahun. Untuk pelaku UMKM diatas 5 tahun sebanyak 16 pelaku UMKM di industri kuliner dan sisanya bergerak pada industri kreatif.

\section{Model Pengukuran (Outer Model)}

Penilaian outer model menggunakan kriteria convergent validity, discriminant validity, composite reliability, cronbach alpha dan average variance extracted. Penilaian convergent validity berdasarkan korelasi antara item score yang diestimasi (Standardized Loading Factor). Untuk mengetahui informasi tentang indikator yang paling berkaitan erat dengan variabel penelitian yaitu melihat indikator yang memiliki loading factor paling besar.

Tabel 2: Convergent Validity dan Composite Reliability

\begin{tabular}{llrlll}
\hline $\begin{array}{c}\text { Laten } \\
\text { Variabel }\end{array}$ & Item & \multicolumn{1}{c}{ SLF } & AVE & CR & CA \\
\hline Orientasi & OT2 & 0,559 & & & \\
Kewira & OT3 & 0,442 & 0,231 & 0,410 & $-0,059$ \\
usahaan & OT4 & $-0,162$ & & & \\
& IN1 & 0,198 & & & \\
& IN2 & $-0,557$ & 0,254 & 0,078 & 0,129 \\
& IN3 & 0,815 & & & \\
& IN4 & 0,046 & & & \\
& PR1 & 0,318 & & & \\
& PR2 & 0,985 & 0,357 & 0,462 & 0,225 \\
& PR3 & $-0,017$ & & & \\
& RI1 & $-0,138$ & & & \\
& RI2 & $-0,663$ & 0,346 & 0,001 & 0,236 \\
Kinerja & RI3 & 0,761 & & & \\
UMKM & PERF1 & 0,265 & & & \\
& PERF2 & 0,447 & 0,375 & 0,588 & $-0,091$ \\
\hline Sumber: Dat & PERF3 & 0,925 & & & \\
\hline
\end{tabular}

Sumber: Data diolah (2020)

Berdasarkan hasil pengujian evaluasi model pengukuran, menunjukan bahwa hanya beberapa indikator dalam setiap konstruk 
yang mempunyai nilai standardized loading factor $(S L F)$ di atas 0,7 ; indikator lainnya bernilai kurang dari 0,5. Nilai $S L F$ 0,5 masih dapat diterima dalam evaluasi model pengukuran (Hair, et al, 2019). Selanjutnya, nilai $A V E$ untuk entrepreneurial marketing, innovative capability dan sustainable competitive advantage lebih kecil dari 0,5. Dari hasil analisis memberikan nilai Composite Reliability dan $C A$ untuk setiap variabel mempunyai nilai lebih kecil dari 0,7.

Selanjutnya, dihitung juga validitas diskriminan untuk melihat korelasi tertinggi dari indikator dengan indikator lainnya. Berdasarkan Tabel 2, indikator IN4 merupakan indikator terbesar dibanding indikator lain dalam inovasi. Indikator terbesar otonom adalah indikator OT1 dan indikator PR2 merupakan indikator terbesar dalam proaktif, sedangkan indikator RI1 merupakan indikator terbesar dibanding indikator lainnya dalam resiko.

Tabel 3. Validitas Diskriminan

\begin{tabular}{lrrrrr}
\hline & Inovasi & Otonom & Proaktif & Resiko & $\begin{array}{r}\text { Kinerja } \\
\text { UMKM }\end{array}$ \\
\hline IN1 & 0,198 & $-0,120$ & 0,033 & $-0,028$ & $-0,072$ \\
IN2 & $-0,557$ & 0,112 & 0,012 & 0,053 & 0,170 \\
IN3 & $-0,557$ & $-0,131$ & $-0,150$ & 0,013 & $-0,250$ \\
IN4 & $\mathbf{0 , 8 1 5}$ & $-0,035$ & $-0,103$ & $-0,118$ & 0,033 \\
OT1 & $-0,107$ & $\mathbf{0 , 6 2 4}$ & 0,168 & 0,044 & 0,263 \\
OT2 & $-0,250$ & 0,559 & 0,005 & $-0,147$ & 0,257 \\
OT3 & 0,144 & 0,442 & 0,039 & 0,016 & 0,149 \\
OT4 & 0,034 & $-0,162$ & $-0,069$ & $-0,106$ & $-0,062$ \\
PR1 & $-0,073$ & 0,040 & 0,318 & $-0,100$ & 0,050 \\
PR2 & $-0,100$ & 0,148 & $\mathbf{0 , 9 8 5}$ & $-0,009$ & 0,271 \\
PR3 & $-0,012$ & 0,148 & $-0,017$ & 0,020 & $-0,006$ \\
RI1 & $-0,081$ & 0,085 & 0,044 & $-0,138$ & 0,043 \\
RI2 & $-0,071$ & $-0,104$ & 0,152 & $-0,663$ & 0,136 \\
RI3 & $-0,101$ & $-0,175$ & 0,106 & $\mathbf{0 , 7 6 1}$ & $-0,157$ \\
PERF1 & 0,015 & 0,015 & 0,127 & $-0,069$ & 0,265 \\
PERF2 & 0,172 & 0,172 & 0,171 & $-0,127$ & 0,447 \\
PERF3 & 0,410 & 0,410 & 0,219 & $-0,177$ & 0,925 \\
\hline Sumber: & Peng01ahan &
\end{tabular}

Sumber: Pengolahan Data (2020)

\section{Evaluasi Struktural Model (Inner Model)} Penelitian ini menggunakan variance-based SEM untuk menjawab pengaruh orientasi kewirausahaan terhadap kinerja UMKM. Adapun Model Standarized dan Model $T$ Value dalam penelitian ini bisa dilihat pada Gambar 1 dan 2 berikut ini.

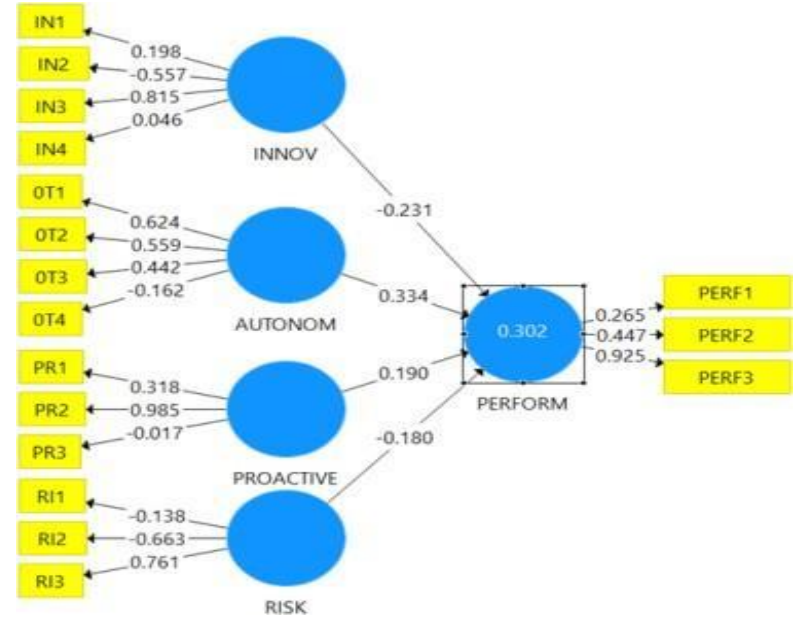

Gambar 1 : Model Standardized Sumber: Penelitian (2020)

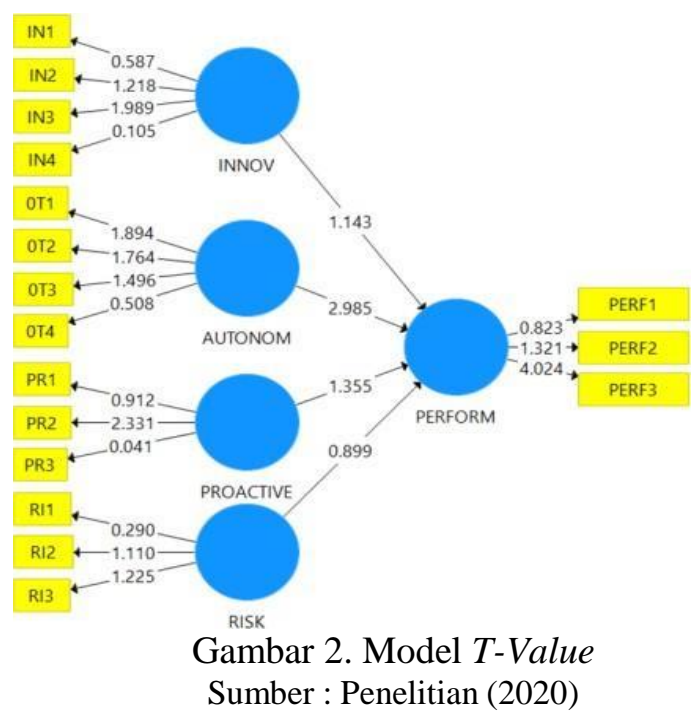

Tabel 4. Pengujian Hipotesis

\begin{tabular}{ccccccc}
\hline $\begin{array}{c}\text { Tu } \\
\text { juan }\end{array}$ & $\begin{array}{c}\text { Hipo } \\
\text { tesis }\end{array}$ & Std & $\begin{array}{c}\text { T-stat } \\
\text { (Gam } \\
\text { bar 1) }\end{array}$ & $\begin{array}{c}P \text { Value } \\
\text { (Gam } \\
\text { bar 2) }\end{array}$ & $\begin{array}{c}\text { Kepu } \\
\text { tusan }\end{array}$ & $\begin{array}{c}R \text { - } \\
\text { Squa } \\
\text { re }\end{array}$ \\
\hline 1 & IN-PERF & $-0,231$ & 1,143 & 0,254 & $\begin{array}{c}\text { H1 } \\
\text { ditolak }\end{array}$ & 0,30 \\
2 \\
2 & OT-PERF & 0,334 & 2,985 & 0,003 & $\begin{array}{c}\text { H1 } \\
\text { diteri } \\
\text { ma }\end{array}$ & $\begin{array}{c}\text { H1 } \\
\text { ditolak } \\
\text { H1 }\end{array}$ \\
& PR-PERF & 0,19 & 1,355 & 0,176 & \\
4 & RI-PERF & $-0,18$ & 0,899 & 0,369 & \begin{tabular}{c} 
ditolak \\
\hline
\end{tabular} \\
\hline
\end{tabular}

Sumber: Pengolahan Data (2020)

Tabel 4 tentang pengujian hipotesis memberikan hasil $R$ Square sebesar 0,302. Hal ini memberikan hasil interprestasi bahwa konstruk orientasi kewirausahaan berpengaruh terhadap konstruk kinerja UMKM sebesar 30,2\%. Selanjutnya, pengujian hipotesis untuk otonom 
berpengaruh terhadap kinerja UMKM dapat diterima karena nilai $t$-value 2,985 dengan $P$ value 0,0003 . Sedangkan hipotesis yang lainnya tidak diterima.

\section{Evaluasi $Q^{2}$}

Model mempunyai nilai predictive relevance jika nilai $Q$-square lebih besar 0 . Berdasarkan hasil penghitungan, model tersebut mempunyai nilai predictive relevance yang baik karena $Q$-square memiliki nilai 0,892

\section{Evaluasi $\boldsymbol{F}$-Square}

Nilai F-Square dapat menjelaskan pengaruh variabel prediktor terhadap variabel dependen, dengan ukuran pengaruh $\mathrm{f}^{2}$ sebagai berikut:

- Jika nilai $\mathrm{f}^{2}$ sebesar 0,02 artinya pengaruh lemah

- Apabila $\mathrm{f}^{2}$ bernilai sebesar 0,15 mengindikasikan pengaruh cukup (moderate)

- Sedangkan pengaruhnya kuat dengan nilai $\mathrm{f}^{2}$ sebesar 0,35

Tabel 5. Pengujian F-Square

\begin{tabular}{cccc}
\hline Tujuan & Variabel & $F$-Square & Effect Size \\
\hline 1 & IN-PERF & 0,073 & Lemah \\
2 & OT-PERF & 0,151 & Moderate \\
3 & PR-PERF & 0,050 & Lemah \\
4 & RI-PERF & 0,046 & Lemah \\
\hline
\end{tabular}

Sumber: Pengolahan Data (2020)

Berdasarkan Tabel 5, hasil pengujian $F$ Square menunjukan tentang hubungan antar variabel otonom dengan kinerja UMKM memiliki pengaruh cukup dalam model structural karena nilai $F$ Square 0,151. Sedangkan hubungan variablel yang lainnya adalah lemah.

\section{Implikasi dari Temuan}

Orientasi kewirausahaan telah digunakan sebagai sumber daya perusahaan (Barney, 1991), pandangan berbasis sumber daya berwujud dan tidak berwujud. Dalam lingkungan bisnis modern, sumber daya tidak berwujud lebih berpengaruh terhadap kinerja (Connor, 2002). Oleh karena itu, pemilik atau pimpinan perusahaan harus berinvestasi pada sumber daya berwujud dan tidak berwujud untuk menciptakan keunggulan kompetitif, hal ini berlaku juga bagi pelaku UMKM. Hasil penelitian orientasi kewirausahaan menunjukan pengaruh positif terhadap kinerja UMKM, sejalan dengan pandangan berbasis sumber daya sebagai keunggulan kompetitif perusahaan (Mustafa, Short, \& Fan, 2015). Kinerja UMKM dalam ukuran pertumbuhan seperti pertumbuhan aset, jumlah penjualan dan jumlah karyawan menunjukkan kinerja yang kurang baik dikarenakan perolehan pendapatan dari UMKM dipergunakan untuk menopang kehidupan wirausahawan untuk mengakumulasi kekayaan yang terkait. Mungkin tidak tepat untuk melakukan klaim bahwa kinerja UMKM yang kurang baik sementara gaya hidup pemilik berubah secara positif.

Hasil penelitian menunjukan bahwa inovatif yang dilakukan pelaku UMKM belum maksimal dan masih harus dikembangkan, sehingga pelaku usaha dalam menerapkan inovasi dalam bisnisnya tidak mempunyai pengaruh nyata dalam kinerja UMKM. Hasil penelitian ini berbeda hasilnya dengan jurnal penelitian yang telah ada (Gupta, Malhotra, Czinkota, \& Foroudi, 2016). Setiap pelaku usaha menyadari pentingnya berinovasi dalam menciptakan kreativitas baik inovasi pada produk, jasa pelayanan, tehnologi dan pemasaran (Lumpkin \& Dess, 2001), setiap perusahaan yang berinovasi pasti menuju keberhasilan karena ide baru mampu mencari peluang yang ada. (Dess \& Lumpkin, 2005), inovasi lebih fokus pada inovasi produk daripada inovasi pemasaran, dengan mengubah atau menambah produk yang di tawarkan kepada pembeli lebih dominan dalam membentuk orientasi kewirausahaan. Inovasi memberikan dukungan atas produk, layanan, proses yang baru bahkan berinisiatif mencari hal-hal yang baru (Miller, 1983). Hasil penelitian pada konstruk item ke 4 menunjukan bahwa pelaku usaha kurang mengalokasikan dana untuk pengembangan produk baru. Adanya pandemi Covid-19 mengakibatkan kelesuan dalam pendapatan bagi pelaku usaha karena efek dari social 
distancing. Misalnya masyarakat tidak bisa menghadiri pertemuan bisnis, rekreasi, acara keluarga dan sebagainya sehingga penyampaian produk dan jasa dari produsen ke konsumen menjadi terhambat. Bagi pelaku usaha langkah inovasi sulit dilakukan terutama inovasi produk yang sangat membutuhkan biaya tinggi karena dana yang ada dipergunakan untuk operasional saja. Namun tidak semua inovasi layak diterapkan untuk bangkit dari kepurukan. Inovasi produk dengan mengenalkan produk baru ke konsumen sulit dilakukan, karena produk baru memerlukan biaya yang tinggi terutama pada kondisi daya beli konsumen yang menurun. Jadi pelaku usaha harus berinovasi dalam penyampaian produk ke konsumen dengan menggunakan media online. Misalnya pelaku usaha menawarkan produk makanan secara online dan delivery service. Bagi industri batik mengalihkan produk fashion dari pakaian jadi menjadi masker atau pelindung diri yang lainnya. Semakin sering berinovasi maka akan meningkatkan kinerja bisnis namun tetap memperhatikan sumber daya yang dimiliki dan aksesibilitas pasar dimana konsumen lebih memilih berbelanja pada barang kebutuhan yang penting dan mendesak. Mengingat pentingnya inovasi diharapkan pelaku UMKM lebih meningkatkan inovatifnya sebagai bagian dari dimensi orientasi kewirausahaan.

Penelitian ini menunjukan hasil bahwa pelaku usaha tidak berani mengambil resiko sehingga pengaruh terhadap kinerja bisnisnya tidak signifikan, sejalan dengan penelitian sebelumnya (Peters, Kallmuenzer, \& Buhalis, 2019). Temuan ini kemungkinan juga dari sifat pelaku UMKM kurang berani mengambil resiko, atau menghindari risiko karena ketidakstabilan dalam ekonomi terutama di masa pandemi Covid-19. Pelaku usaha harus berani mengambil resiko bisnis, yang merupakan salah satu dimensi dari orientasi kewirausahaan (McGrath, MacMillan, Yang, \& Tsai, 1992) dan kegagalan satu usaha seharusnya tidak menghentikan memulai yang lain, karena pengalaman seperti itu merupakan faktor penting yang akan menjadi sumber daya yang bermanfaat bagi pertumbuhan bisnis di masa depan (Kreiser, Anderson, Kuratko, \& Marino, 2019), sebagian besar perusahaan merasa lebih nyaman jika lingkungan eksternal yang statis dibandingkan perubahan lingkungan dinamis. Kecemasan tinggi jika menghadapi tantangan perubahan lingkungan yang cepat. Menurut Kreiser et al. (2019), perusahaan cenderung menghindari ketidakpastian dan menginvestasikan sumber daya ke usaha yang sedikit resikonya. . Seharusnya pemilik usaha yang baik harus fokus pada langkah usaha baru yang memiliki resiko tinggi dan agresif mencari peluang potensial dalam menghadapi kondisi ketidakpastian (Miller, 1983). Pada konstruk item ke 3 hasil penelitian menunjukan sebagian besar pelaku UMKM kurang berani mengambil berbagai tindakan yang diperlukan untuk mencapai tujuan. Responden kurang yakin bagaimana bisnis mereka mengadopsi jenis tindakan dalam menghadapi resiko secara berhati-hati atau agresif. Pandemi Covid-19 berdampak besar pada semua sektor bisnis terutama UMKM yang sebagian besar tidak mempunyai cadangan kas seperti perusahaan besar. Kebutuhan bagi pelaku usaha sangat tinggi, termasuk biaya operasional terus meningkat karena kondisi ekonomi yang belum stabil dan gangguan terhadap rantai pasokan adanya kebijakan menjaga jarak sosial sehingga pelaku usaha sangat berhati-hati dalam mengambil tindakan berbisnis. Walaupun krisis, pelaku usaha harus mengambil resiko untuk keberlangsungan bisnisnya dan resiko yang diambil akan berdampak pada kondisi perusahaan nantinya. Pilihan yang akan diambil misalnya mengurangi pegawai, menutup usaha, meminjam dana dari perbankan atau memaksimalkan potensi yang dimiliki merupakan bagian dari resiko terutama bagi karyawan dan perusahaan. Dengan tidak mengambil resiko justru lebih beresiko. Hasil riset McKinsey menyatakan bahwa konsumen Indonesia selama masa pandemi mengaku mengalami penurunan pemasukan dan tabungan, namun tetap menunjukkan aktivitas konsumsi yang lebih tinggi. Hal ini menunjukkan adanya peluang 
yang tersedia bagi pelaku bisnis. Pemerintah RI memberikan bantuan bagi UMKM yang terdampak krisis pandemi COVID-19 dengan skema bantuan bagi UMKM melalui mekanisme moneter bagi UMKM yang masih dapat bertahan di tengah krisis pandemi COVID-19 dan bantuan sosial bagi UMKM yang sama sekali sudah tidak mampu lagi melaksanakan kegiatan penjualan. Selain itu Pemerintah RI juga melakukan progam pendampingan dengan korporasi besar. Misalnya PT Unilever Indonesia Tbk. memberikan pembinaan dan bantuan produksi hingga pemasaran agar rantai bisnis UMKM dapat kembali pulih. Sedangkan pemerintah RI memberikan insentif kredit bagi korporasi yang turut serta dalam program tersebut.

Menurut Bell, McNaughton, Young, dan Crick (2003), proaktif memiliki kemampuan yang lemah untuk kinerja UMKM sejalan dengan hasil penelitian. Proaktif merupakan sarana yang berhubungan dengan ketidakpastian dalam menjalankan usaha. Proaktif dapat diwujudkan ketika struktur organisasi mendukung perilaku proaktif yang mendorong peningkatan keunggulan kompetitif. Untuk menghadapi ancaman faktor eksternal perusahaan, diperlukan inisiatif dari pelaku usaha (Rauch, Wiklund, Lumpkin, \& Frese, 2009), dalam menerapkan ide dan pemikiran yang kreatif. Hasil penelitian konstruk proaktif item kedua, pelaku UMKM bukan yang pertama kali memperkenalkan suatu produk. Kemungkinan adanya ketakutan apabila melihat banyaknya pesaing sehingga kurang tertantang mengembangkan ide-ide produk baru dan mengesplorasi peluang secara cepat. Selain itu pelaku usaha kurang proaktif dalam mengenalkan suatu produk disebabkan oleh kelesuan pendapatan. Dalam menghadapi pandemi Covid-19 pelaku usaha harus mengambil inisiatif dan berupaya memberikan pengaruh serta melakukan perubahan. Pelaku usaha tidak pasif namun beradaptasi dengan perubahan, misalnya melakukan substitusi produk. Melonjaknya permintaan masker, memberi peluang kepada pelaku usaha memproduksi masker kain sebagai produk substitusi dari masker kesehatan. Dalam tindakan proaktif, pelaku usaha perlu mengumpulkan informasi dalam menghadapi dan bereaksi terhadap perubahan lingkungan pasar. Dalam mengatasi pesaing dalam masa pandemi Covid-19, walaupun sebagai follower suatu produk namun kualitas barang atau jasa lebih ditingkatkan. Selain itu memanfaatkan teknologi secara lebih optimal sehingga efisiensi waktu dan uang, misalnya dengan sistem online delivery dan meningkatkan skill agar dapat mendukung perkembangan tehnologi.

Otonom, salah satu dimensi pembentuk orientasi kewirausahaan (Lumpkin \& Dess, 2001). Dalam penelitian ini, konstruk otonom terdiri dari 4 (empat) item yaitu: karyawan diberikan kebebasan untuk mempraktikkan ketrampilannya, mendukung karyawan untuk menghasilkan produk baru, memberdayakan karyawan untuk membuat keputusan dan keleluasaan dalam menjalankan tugas, seperti penjadwalan bekerja. Menurut Dess dan Lumpkin (2005), dimensi otonom dalam orientasi kewirausahaan adalah pelaku usaha memberikan kebebasan bagi anggotanya baik secara individu atau bersama-sama dalam memberikan ide dan saran untuk mencapai keberhasilan tujuan. Otonomi kewirausahaan menawarkan kesempatan kepada perusahaan bekerja sesuai dengan tujuan, nilai, selera, dan keyakinan mereka sendiri. Perusahaan mungkin senang melakukan urusannya sendiri, atau melakukan sesuatu dengan cara tertentu, tetapi pelanggan mungkin ingin dia bekerja sesuai dengan spesifikasinya. Otonomi kewirausahaan berarti memiliki kebebasan memutuskan berkaitan dengan apa, bagaimana, dan kapan pekerjaan yang terkait dengan usaha akan dilakukan, termasuk pengaturan arah strategis perusahaan. Hasil penelitian sejalan dengan (Boso et al., 2013), otonom merupakan komponen penting dari orientasi kewirausahaan. Karyawan diberikan kebebasan untuk mempraktikan ketrampilan pada konstruk otonom item keempat sesuai dengan (Lumpkin et al., 2009) menyarankan 
pemberian otonomi kepada karyawan dapat memotivasi mereka untuk bertindak secara kewirausahaan dan meningkatkan kinerja UMKM. Oleh karena itu disarankan pemberian otonomi kepada karyawan untuk dapat memotivasi mereka untuk bertindak secara kewirausahaan sehingga dapat meningkatkan kinerja UMKM. Dalam hal ini, karyawan bisa diberikan kebebasan untuk mempraktikkan ketrampilannya, mendukung karyawan untuk menghasilkan produk baru, memberdayakan karyawan untuk membuat keputusan dan keleluasaan dalam menjalankan tugas, seperti penjadwalan bekerja, serta memberikan kebebasan secara individu atau bersama-sama dalam memberikan ide dan saran.

\section{Kesimpulan}

Berdasarkan pada hasil penelitian menunjukkan bahwa dari orientasi kewirausahaan yang mempunyai pengaruh terhadap kinerja UMKM hanya dimensi otonom. Sedangkan dimensi orientasi kewirausahaan yang lainnya: inovasi, proaktif dan resiko tidak berpengaruh signifikan terhadap kinerja UMKM. Oleh karena itu disarankan pemberian otonomi kepada karyawan untuk dapat memotivasi mereka dengan memberikan kebebasan untuk bertindak secara kewirausahaan sehingga dapat meningkatkan kinerja UMKM. Dalam hal ini, karyawan bis a diberikan kebebasan untuk mempraktikkan ketrampilannya, mendukung karyawan untuk menghasilkan produk baru, memberdayakan karyawan untuk membuat keputusan dan keleluasaan dalam menjalankan tugas, seperti penjadwalan bekerja, serta memberikan kebebasan secara individu atau bersamasama dalam memberikan ide dan saran. Selain itu, secara umum, pelaku UMKM harus berupaya meningkatkan orientasi kewirausahaan supaya tetap kompetitif dan berkelanjutan.

\section{DAFTAR PUSTAKA}

Agu, M. (2018). Infrastructural development and growth of micro small and medium scale enterprises (MSME). Academic
Journal of Economic Stusies, 4(4), 7177.

Ajayi, B. (2016). The impact of entrepreneurial orientation and networking capabilities on the export performance of nigerian agricultural SMEs. Journal of Entrepreneurship and Innovation in Emerging Economies, 2(1), 1-23. https://doi.org/10.1177/2393957515619 720

Al-Dhaafri, H. S., \& Al-Swidi, A. (2016). The impact of Total Quality Management on organizational performance. Journal of Department of Business Administration, 33(5).

Al Mamun, A., \& Fazal, S. A. (2018). Effect of entrepreneurial orientation on competency and micro-enterprise performance. Asia Pacific Journal of Innovation and Entrepreneurship, 12(3), 379-398. https://doi.org/10.1108/apjie05-2018-0033

Arshad, A. S., Rasli, A., Arshad, A. A., \& Zain, Z. M. (2014). The impact of entrepreneurial orientation on business performance: a study of technologybased smes in malaysia. Procedia Social and Behavioral Sciences, 130(1996), 46-53. https://doi.org/10.1016/j.sbspro.2014.04 .006

Barney, J. (1991). Firm resources and sustained competitive advantage. Journal of Management, 17(1), 99-120. Retrieved

from https://doi.org/10.1177\%2F0149206391 01700108

Bell, J., McNaughton, R., Young, S., \& Crick, D. (2003). Towards an integrative model of small firm internationalisation. Journal of International Entrepreneurship, 1(4), 339-362. https://doi.org/10.1023/A:10256294240 41

Bolton, D. L., \& Lane, M. D. (2012). Individual entrepreneurial orientation: Development of a measurement instrument. Education and Training, $54(2-3)$, 
https://doi.org/10.1108/0040091121121 0314

Boso, N., Story, V. M., \& Cadogan, J. W. (2013). Entrepreneurial orientation, market orientation, network ties, and performance: Study of entrepreneurial firms in a developing economy. Journal of Business Venturing, 28(6), 708-727. https://doi.org/10.1016/j.jbusvent.2013. 04.001

Budastra, I. K. (2020). Socio-economic impacts of covid-19 and potential programs for mitigation : a case study in Lombok Barat District. Jurnal Agrimansion, 20(1), 48-57.

CNN. 2020. Omzet UMKM Anjlok 75 \%karena Corona. CNN Indonesia Kamis, 06/08/2020 15:49 WIB diakses tanggal 5 November 2020

Connor, T. (2002). The resource-based view of strategy and its value to practising managers. Strategic Change, 11(6), 307-316. https://doi.org/10.1002/jsc.593

Covin, J. G., \& Miles, M. P. (1999). Corporate entrepreneurship and the pursuit of competitive advantage. Entrepreneurship Theory and Practice, 23(3), 47-63. https://doi.org/10.1177/1042258799023 00304

Curado, C., Muñoz-Pascual, L., \& Galende, J. (2018). Antecedents to innovation performance in SMEs: A mixed methods approach. Journal of Business Research, 89(June 2017), 206-215. https://doi.org/10.1016/j.jbusres.2017.1 2.056

Davidsson, P. (2015). Entrepreneurial opportunities and the entrepreneurship nexus: A re-conceptualization. Journal of Business Venturing, 30(5), 674-695. https://doi.org/10.1016/j.jbusvent.2015. 01.002

Dess, G. ., \& Lumpkin, G. (2005). The role of entrepreneurial orientation in simulating effective corporate entrepreneurship. Academy of Management Executive, 19(1), 147-156. https://doi.org/10.1177/0022487182033
00610

Ferreira, J. J., Azevedo, S. G., \& Ortiz, R. F. (2011). Contribution of resource-based view and entrepreneurial orientation on small firm growth. Cuadernos de Gestion, 11(1), 95-116. https://doi.org/10.5295/cdg.100185jf

Friesen, P., \& Miller, D. (1982). innovation in conservative and entrepreneurial firms: two models of strategic momentum. Strategic Management Journal, 3(December 1980), 1-25.

Garud, R., Tuertscher, P., \& Van de Hen, A. (2013). Perspectives on innovation Processes. The Academy of Management Annals, 7(1), 775-819.

Gupta, S., Malhotra, N. K., Czinkota, M., \& Foroudi, P. (2016). Marketing innovation: A consequence of competitiveness. Journal of Business Research, 69(12), 5671-5681. https://doi.org/10.1016/j.jbusres.2016.0 2.042

Hadi, S., \& Supardi, S. (2020). Revitalization strategy for small and medium enterprises after corona virus disease pandemic (Covid-19) in Yogyakarta. Journal of Xi'an University of Architecture \& Technology, XII(IV). https://doi.org/10.37896/jxat12.04/1149

Inauen, M., \& Schenker-Wicki, A. (2011). The impact of outside-in open innovation on innovation performance. European Journal of Innovation Management, 14(4), 496-520. https://doi.org/10.1108/1460106111117 4934

Karacaoglu, K., Bayrakdaroglu, A., \& San, F. B. (2012). The impact of corporate entrepreneurship on firms' financial performance: evidence from istanbul stock exchange firms. International Business Research, 6(1), 163-175. https://doi.org/10.5539/ibr.v6n1p163

Kor, Y. Y., \& Mahoney, J. T. (2004). Edith Penrose's (1959) Contributions to the resource-based view of strategic management. Journal of Management Studies, 41(1), 183-191. https://doi.org/10.1111/j.1467- 
6486.2004.00427.x

Kotane, I., \& Kuzmina-Merlino, I. (2017). Analysis of small and medium sized enterprises' business performance evaluation practice at transportation and storage services sector in Latvia. Procedia Engineering, 178(June), 182191.

https://doi.org/10.1016/j.proeng.2017.0 1.093

Kreiser, P. M., Anderson, B. S., Kuratko, D. F., \& Marino, L. D. (2019). Entrepreneurial orientation and environmental hostility: A threat rigidity perspective. Entrepreneurship: Theory and Practice, 44(6), 1174-1198. https://doi.org/10.1177/1042258719891 389

Laufs, K., \& Schwens, C. (2014). Foreign market entry mode choice of small and medium-sized enterprises: A systematic review and future research agenda. International Business Review, 23(6), 1109-1126.

https://doi.org/10.1016/j.ibusrev.2014.0 3.006

Lawson, B., \& Samson, D. (2001). Developing innovation capability in organisations: a dynamic introduction review of the literature. International Journal of Innovation Management, 5(3), 377-400.

Liu, H., Ding, X. hao, Guo, H., \& Luo, J. hui. (2014). How does slack affect product innovation in high-tech Chinese firms: The contingent value of entrepreneurial orientation. Asia Pacific Journal of Management, 31(1), 47-68. https://doi.org/10.1007/s10490-0129309-5

Lumpkin, G. ., Cogliser, C. C., \& Schneider, D. R. (2009). E T \& P understanding and measuring autonomy: An entrepreneurial orientation prespective. Seizure, 14(806), 47-70. Retrieved from http://www.ncbi.nlm.nih.gov/entrez/que ry.fcgi? $\mathrm{cmd}=$ Retrieve $\& \mathrm{db}=\mathrm{PubMed} \& \mathrm{~d}$ $\mathrm{opt}=$ Citation\&list_uids $=15642502$

Lumpkin, G. ., \& Dess, G. G. (2001). Linking two dimensions of entrepreneurial orientation to firm performance: the moderating role of environment and industry life cycle. Journal of Business Venturing, 16(3), 429-451.

McGrath, R. G., MacMillan, I. C., Yang, E. A. Y., \& Tsai, W. (1992). Does culture endure, or is it malleable? Issues for entrepreneurial economic development. Journal of Business Venturing, 7(6), 441-458. https://doi.org/10.1016/08839026(92)90019-N

Miller, D. (1983). The correlates of entrepreneurship in Three Types of Firms. Management Science, 29(7), 770-791.

https://doi.org/10.1287/mnsc.29.7.770

Muafi, M. (2020). A nexus among strategic orientation, social network, knowledge sharing, organizational innovation, and MSMEs performance. Journal of Asian Finance, Economics and Business, 17(6), 327-338. https://doi.org/10.13106/jafeb.2020.vol 7.no6.327

Murphy, G., Trailer, J., \& Hill, R. (1996). Measuring research performance in

entrepreneurship. Journal of Business Research, 36(1), 15-23.

Mustafa, H. R., Short, M., \& Fan, S. (2015). Social support exchanges in facebook social support group. Procedia - Social and Behavioral Sciences, 185, 346-351. https://doi.org/10.1016/j.sbspro.2015.03 .449

Penrose, E. T. (1959). The theory of the growth of the firm. New York: John Wiley

Parida, V., Westerberg, M., \& Frishammar, J. (2012). Inbound open innovation activities in high-tech smes: the impact on innovation performance. Journal of Small Business Management, 50(2), 283-309.

https://doi.org/10.1111/j.1540627X.2012.00354.X

Pérez-Luño, A., Wiklund, J., \& Cabrera, R. V. (2011). The dual nature of innovative activity: How entrepreneurial orientation influences innovation generation and adoption. Journal of Business Venturing, 
26(5),

$555-571$

https://doi.org/10.1016/j.jbusvent.2010.

03.001

Peters, M., Kallmuenzer, A., \& Buhalis, D. (2019). Hospitality entrepreneurs managing quality of life and business growth. Current Issues in Tourism, 22(16), 2014-2033. https://doi.org/10.1080/13683500.2018. 1437122

Rauch, A., Wiklund, J., Lumpkin, G. T., \& Frese, M. (2009). Entrepreneurial orientation and business performance: An assessment of past research and suggestions for the future. Entrepreneurship: Theory and Practice, 33(3), 761-787. https://doi.org/10.1111/j.15406520.2009.00308.x

Rumelt, R. P. (1991). Does industry matter? Strategic Management Journal, 185(12), 167-185.

Sandy, K. F. Survei BI: 72,6 \%UMKM Turun Omzet akibat Pandemi Covid-19. www.inews.id. Kamis, 08 Oktober 2020 - 12:20:00 WIB diakses tanggal 10 November 2020

Sekaran, Uma, Bougie, Roger. (2020). Research Methods For Business : A Skill Building Approach (8th ed. (Asia Edition)). Hoboken: Wiley

Shepherd, D., \& Wiklund, J. (2009). E T \& P Are we comparing apples with apples or apples with oranges? appropriateness of knowledge accumulation across growth studies. Journal of Management, 3(1), 105-124.

Sohn, S. Y., Gyu Joo, Y., \& Kyu Han, H. (2007). Structural equation model for the evaluation of national funding on R\&D project of SMEs in consideration with MBNQA criteria. Evaluation and Program Planning, 30(1), 10-20. https://doi.org/10.1016/j.evalprogplan.2 006.10 .002

Theriou, N. G. (2015). Strategic management process and the importance of structured formality, financial and non-financial information. European Research Studies Journal, 18(2), 3-28.
Wang, C. L. (2008). Entrepreneurial orientation, learning orientation, and firm performance. Entrepreneurship Theory and Practise, 4(32), 635-657. https://doi.org/10.1108/sd-07-20160110

Weerawardena, J., \& O'Cass, A. (2004). Exploring the characteristics of the market-driven firms and antecedents to sustained competitive advantage. Industrial Marketing Management, 33(5), 419-428. https://doi.org/10.1016/j.indmarman.20 03.07.002

Wolff, J. A., \& Pett, T. L. (2006). Small-firm performance: Modeling the role of product and process improvements. Journal of Small Business Management, 44(2), 268-284. https://doi.org/10.1111/j.1540627X.2006.00167.x

http://www.depkop.go.id/data-umkm http://diskopukm.jatimprov.go.id/berita?per_ page $=126$

Radar Surabaya, Jawa Pos 1 Mei 2020 